\title{
River systems in transition: pathways and stakeholder involvement
}

\author{
W. Ravesteijn ${ }^{1}$, O. Kroesen ${ }^{1}$, F. Firoozyar ${ }^{1} \&$ X. Song ${ }^{2}$ \\ ${ }^{I}$ Section of Technology Dynamics \& Sustainable Development, \\ Delft University of Technology, The Netherlands \\ ${ }^{2}$ Department of Industrial Ecology, Royal Institute of Technology, \\ Stockholm, Sweden
}

\begin{abstract}
In view of present-day water stress, water transitions are necessary, incorporating both technological innovation and institutional reform. Water provisions and problems involve a range of diverging interests and values, with which a corresponding range of actors and stakeholders are connected. This paper focuses on both the social and the technological dynamics around river development and management, and explores the margins and possibilities of stakeholder involvement in water transitions. It draws on cases from The Netherlands, Bangladesh and China.

Keywords: river systems, socio-technical systems, technological regimes, stakeholder involvement, water transitions.
\end{abstract}

\section{Introduction}

Water managers and developers face a variety of sustainability problems and they are challenged to seek solutions in order to secure - and improve - the broad range of services that water systems deliver [1]. In fact, the scope of the challenges is such that complete "transitions" are necessary, radical changes of water systems, incorporating not only technological innovation but also institutional reform. Water provisions and problems involve a range of diverging interests and values, with which a corresponding range of actors and stakeholders are connected. Consequently, stakeholder involvement is generally considered a necessity in solving water problems and realizing water transitions, though worldwide in varying degrees. The question, however, is to what extent 
stakeholder participation is possible, given the constraints of existing water systems and their context. This paper focuses on both the social and the system dynamics of river engineering and management, and explores the margins and possibilities of stakeholder engagement in water transitions. In doing so it replaces a political discourse (stakeholders are a must!) by a scientific one, using knowledge and insight from Technology Dynamics and Science, Technology and Society [2]. It follows a conceptual and theoretical approach, aspects of which are exemplified and explained by historical and present-day developments in The Netherlands, Bangladesh and China. Ultimately, suggestions are made aimed at keeping transitional processes running, both in general and regarding the cases.

\section{Water: a systems perspective}

A systems approach has a central position in current day thinking about fighting water stress and improving water resources management and development in general [1-8]. Following Hughes' seminal work about "networks of power" [9], systems of infrastructure have been conceptualized as "technological systems" or "socio-technical systems", comprising of complex networks of technical artefacts and all the related social structures [10, 11]. Aimed at fulfilling social needs, these systems are characterized by internal integration and external adaptation. Their development is to a large extent determined by system mechanisms like "reverse salient" (a barrier in system development which forms a focus for creative capabilities) and "momentum" (the mass of the system), though ultimately actors shape and support the system. This socio-technical systems approach has been applied to water systems as well [1, 12]. Sociotechnical system development is governed by "technological regimes", sets of heuristics that guide a technological community in its problem solving activities, rule-sets engineers and other system builders consciously and unconsciously use in their work. These regimes are disciplining activity, but they can also undergo radical change or a "regime shift" [13]. This concept has also been applied to water systems $[14,15]$.

\section{Transitions and trajectories}

A transition is "a structural social change resulting from developments, which interact and reinforce each other, in the fields of economy, culture, technology institutions and nature and environment" [16]. Following the seminal work of Jan Rotmans [16, 17], several researchers have elaborated on his S-curve based transition process. The most influential ones are Geels and Schot [18, 19], who have constructed a three-level model of transitions starting in niches, expanding into regimes and ultimately becoming a part of the broader developments and context of the landscape; the landscape also provides the source of the initial stimuli. However, this process, modelled on the demographic transition model and inspired by the work of the economist Rostow [20], is only one type of transition. In order to do justice to the manifold forms of transitions that have 
been identified, Berkhout et al. [21] and Smith et al. [22] have developed a scheme of socio-technical transformations using two axes: mobilization of resources within or outside of the regime, and low versus high coordination (see fig. 1). These axes reflect the differences between, on the one hand, "society induced technology development" versus "internal technology development" and, on the other hand, top-down versus bottom-up activity.

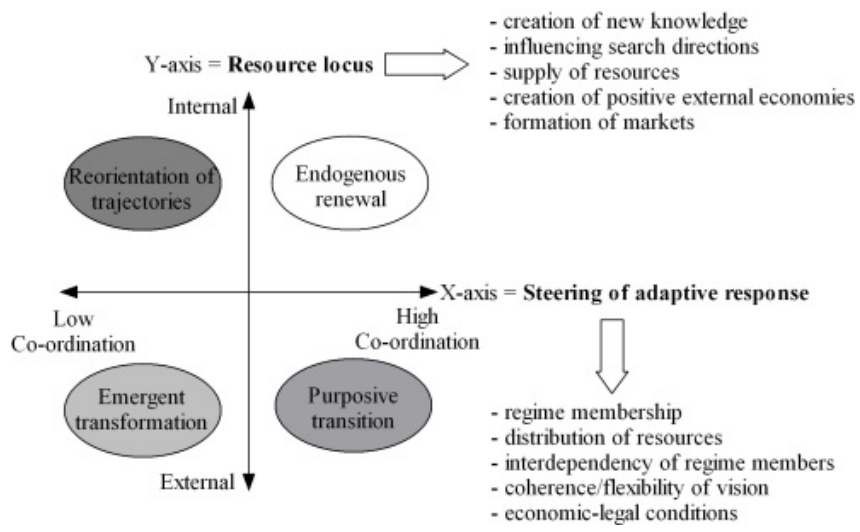

Figure 1: Transition contexts as a function of the degree of coordination to selection pressures and the locus of adaptive resources [22].

This scheme and others (e.g. [18]) suggest that all transitions fit within a specific quadrant. All authors [19, 21, 22] involved, however, indicate that contexts of a socio-technical regime may change, and that a change in context will change the transition pattern. This is much more relevant than what they suggest, as specific transitions are usually a combination of these analytically distinguished patterns. We can take this a step further, suggesting that transitions can only be successful in case one or more of the other quadrants are passed through or touched upon. Top-down steering might be necessary, but bottom-up engagement might be crucial as well, in the domain of both society and technology. Transitions might start as one type, but reorient themselves later on by drawing on new resources or finding support in new coordination situations. Purposive transitions, e.g., need to land in society; they could benefit from internal technology development, coordinated or not. Transitions could also bear the character of one type, but still touch upon other quadrants. No particular succession of pathways seems logical, so sequences could be considered to be contingent and have to be empirically determined.

\section{Intervention tools and stakeholder involvement}

Several parties are involved in technology development, which could be distinguished as actors (like developers and regulators; in general, members of the regime) and stakeholders (like users; parties from outside the regime). Form 
and extent of stakeholder participation depend on the type of transition and are determined by the space and direction of the specific intervention tools which are and have to be used. Each transition trajectory - or trajectory within a transition - requires specially adapted management methods to stimulate its progress. Unilinear transitions might need a specific governance paradigm, e.g. command-andcontrol, the market or a policy network approach [23], as well as related specific management methods. A more realistic multi-linear view of transitions, however, opens a perspective on a wide range of applicable tools, dependent on the character that a transition process assumes at a particular time (see table 1).

Table 1: $\quad$ Transitions and examples of intervention tools.

\begin{tabular}{|l|l|l|}
\hline & External resources & Internal resources \\
\hline $\begin{array}{l}\text { High } \\
\text { coordination } \\
\text { (Top-down) }\end{array}$ & $\begin{array}{l}\text { Purposive transitions: } \\
\text {-Triple Helix }\end{array}$ & $\begin{array}{l}\text { Endogenous renewal: } \\
\text {-Strategic niche management [24] } \\
\text {-Learning processes [26] }\end{array}$ \\
\hline $\begin{array}{l}\text { Low } \\
\text { coordination } \\
\text { (Bottom-up) }\end{array}$ & $\begin{array}{l}\text { Emergent transformation: } \\
\text {-Social network building }\end{array}$ & $\begin{array}{l}\text { Re-orientation of trajectories: } \\
\text {-Technical problem-solving: } \\
\text { reverse salient [9,11] }\end{array}$ \\
\hline
\end{tabular}

In the context of purposive transitions, stakeholder involvement assumes the shape of societal groups being brought together with actors from politics and economy (Triple Helix). When it comes to endogenous renewal, stakeholders are also involved as users. Stakeholders have more important roles to play in the case of emergent transformations, especially when they appear as co-developers of technology. Back-casting is an instrument to form long-term visions with all actors and stakeholders on the basis of which short-term actions are possible. They are less clearly visible in processes of reorientation of trajectories, where they manifest themselves as users of socio-technical systems. In this framework, water transitions could be defined as a combination of socio-technical systems innovations and technological regime shifts, in which the terms "socio-technical system" and "technological regime" are used as orientating concepts. Water transitions may follow a variety of pathways, each giving rise to specific intervention tools and inherent stakeholder arrangements.

\section{Developments and challenges in the water domain}

Civilization started with river control associated with technology and management capabilities and values. By now, most rivers have been engineered under human control. In the process, natural water systems have been turned into multi-functional water systems. A variety of technologies and styles of management and governance have developed, informed by diverging values, capabilities and "imaginary structurations" leading to specific development trajectories or paths [27]. River system development took place under the influence of a series of consecutive technological regimes, from simple to complex and integrated regimes. The last regime shift began with the 
introduction of Integrated River Basin Management (IRBM), which provides a basin-wide approach, multi-purpose management and technological development as well as multi-actor cooperation between the various regions and/or countries involved [6]. IRBM is a non-structural approach, accommodating competing priorities, views and values, which supplements a structural approach: constructing dikes, weirs, reservoirs and various types of canals, including interbasin connections. It is facilitated by modern information and communication technologies, both in collecting and spreading information. System builders are challenged to further develop IRBM, including supplementing technologies.

Sustainable solutions for advanced river control entail value conflicts and ethical issues ensuring a just and fair distribution of available water resources, at all geo-political levels. Socially responsible innovations require processes of interaction and communication between all stakeholders, in which these and other choices are considered and settled. There is already a loose relationship between "integrated water management" and ecologically "sustainable development" [3, 4]. Further development should create the conditions under which IRBM will ensure both ecologically and socially sustainable water development, integrating a diversity of value priorities. Mutual international learning processes and policy transfers, involving different sets of knowledge, priorities, values and capabilities, are at the core of the present challenges. A new generation of value sensitive "policy transplants" has to be developed, considering path-dependent developments as well as mutual learning and capacity building $[28,29]$.

Three tendencies can be noticed in water engineering and management development, processes that are rooted in the past but which nevertheless form the core of and give direction to presently necessary water transitions:

- Increasing complexity: water systems, usually serving various purposes, are linked up with other socio-technical (e.g. energy) systems, reinforcing their multi-actor and multi-functional character. This "system innovation" creates additional tensions and conflicting priorities.

- Expanding IRBM (or: IWRM, Integrated Water Resources Management): accommodates the growing range of water uses. IWRM steers water transitions towards technological regimes that emphasize non-structural rather than structural measures. It relies especially on multi-actor agreements and the accompanying management capabilities.

- A new equilibrium of central control and local optimization: striving for adaptive and resilient, flexible and robust water systems. This involves a shift from a Struggle against Nature to a Living with Nature regime.

Water stress involves complete societies and a multitude of nationalities. All parties involved are equipped with their own views of priorities and solutions, values and capabilities. How could water transitions be stimulated? Obviously, that depends on specific pathways. We will show this in the cases of The Netherlands, Bangladesh and China. The Dutch water history also exemplifies the four distinguished trajectories. It will appear that each transition type is associated with specific intervention tools and, by implication, with specific possibilities and limitations regarding stakeholder participation. 


\section{Water transitions in The Netherlands}

The construction of The Netherlands started around the year 1000 (see for this section: [30-35]). The population of the marshy delta area in the north-west corner of Europe was small but increased, facilitated by an emerging politicaleconomic organization. The future Dutch started their hydraulic activities, initiated by counts and monks, with building dikes for protection against floods from the North Sea and the rivers Rhine, Meuse, Scheldt and Ems. The next step was draining marshes for agricultural purposes. The resulting lowering surface made natural drainage impossible and wind-water mills were introduced to pump the water out. At the same time, grain-cultivation gave way to cattle-breeding.

Starting from the 16th century, land reclamation continued by pumping lakes dry through mills, which were replaced by steam engines in the 19th century. In this way the famous "polders" arose. Water boards were established in which all parties involved were represented. Reclamation activities extended to the seas. First, the embankment of land outside of the dikes occurred in the north (17th century), later on - after a big flood - the complete Zuider Zee in the middle of the country followed (20th century). The new reclaimed land was used for agriculture. The flooding of the rivers was fought with "normalization" or "canalization" in the 19th century, carried out by the new national water agency. The 1953 disaster led to the well-known Delta works, which were completed with a storm surge barrier near Rotterdam in 1997. The Dutch water resources management and development culminated in Integrated Water Management (IWM), formulated in the 1980s, in which all interests are considered.

Present water management in The Netherlands is shaped within the context of European water policies, in the first place IRBM. The international cooperation concerning the Rhine can be considered a pioneering effort. The creation of IRBM stimulates and is conditioned by the post-war European unification process, in which public control measures follow on the establishment of a free market. The 2000 EU Water Frame Directive forms an essential step. It offers a policy framework for protecting and improving the quality of water resources, but is also linked to water quantity control. It contains a precise planning; by 2015 all European waters should be in a "good condition". Against the background of European water policies, the Dutch are experimenting with a new technological regime: the Room for the Water regime, replacing the Dry Feet regime. This shift is supported and implemented by the national water agency, which initiated it in response to flooding problems and threats in the 1990s. Until now, however, social acceptance of this policy is low.

The Dutch water history contains examples of the transition trajectories distinguished here. It all started as an "emergent transformation", in which farmers and other water experts created an environment in which they could thrive. People were connected through networks, which enabled the exchange of knowledge and technology. In retrospect, we might consider this a form of "participatory development", especially when it comes to the water-boards, in which all stakeholders took part, though not in fully democratic ways. However, top-down steering (with Triple Helix like arrangements) and internal technology 
development (e.g. on the basis of learning processes) were or became essential ingredients as well. Meanwhile, activities evolved, from dike building to drainage to the creation of polders. In part, we can characterize these changes as an "endogenous renewal" and as a "reorientation of trajectories", e.g. in the case of changing land reclamation patterns, guided by dominant actors or not.

Solutions to problems caused new problems, e.g. soil subsidence, which had to be solved. Consequently, "reverse salients" were leading the way. Drainage on the basis of gravity became impossible, necessitating windmills. The emergent de-central water management could not handle the big river problems. Although all relevant groups were involved (Triple Helix), it was basically a "purposive transition" through which these problems were solved. However, a "reorientation of trajectories" (from water division to canalization) paved the road to success. Finally, the change-over to the Room for the Water regime could be considered an "endogenous renewal". The national water agency "learned" that dike enforcement could no longer keep The Netherlands safe and it is preparing and experimenting with this new regime in niches. Meanwhile, European IRBM is being adopted and expanded, which could be seen as a "purposive transition". We can conclude that the Dutch water transition history started bottom-up, but could not avoid more central control and purposeful intervention. Decentralized initiatives and developments, however, remained possible and necessary.

\section{Bangladesh: the difficult transition towards river basin management}

In 1990, the Flood Action Plan, a nation-wide water development programme, was launched in Bangladesh (see for this section: [36-39]). Drawn up in reaction to disastrous floods in the late 1980s, it involved huge foreign support, both financially and technologically. The programme was coordinated by the World Bank, at the request of the government of Bangladesh. Consequently, infrastructural works like dikes, polders and sluices were planned and implemented in the beginning of the 1990s.Recently, adverse impacts have become visible. Increasing siltation in canals and rivers led to the lowering of water tables in (wet)lands, heightening of river beds, and reduced conveyance capacity of rivers, resulting in long-term waterlogging, especially in the southwest. Consequently, farmers could not use their rice fields, while roads and villages remained under water. Severe siltation has caused whole rivers to disappear, though the Bangladesh Water Development Board (BWDB) is planning to restore these. However, measures are implemented only slowly, while even local communities feel that constant and repeated dredging of rivers and canals is not a sustainable solution.

By sheer frustration and led by a local NGO a group of farmers in the southwest of Bangladesh started to implement Tidal River Management (TRM), based on opening polders periodically to tidal flows. People see to it that the river drops its silt in a polder, which is temporarily put under water, instead of in its bed. Since this was done without permission of the central authorities, the communities and NGOs involved are now in conflict with the Bangladeshi 
government, represented by the BWDB. One of the issues is that the BWDB wants to remain in control of water management, i.e. the opening and closing of sluices and the decisions about how much water is flowing where. The local farmers and NGOs, however, do not trust the central government on that. They argue that government officials in Dhaka do not care about the problems of the farmers and that decisions on water control should be taken locally anyhow. International donors are mediating, but local communities, remembering their alignment with the BWDB in earlier projects, are suspicious and no progress has been made.

The strongly collectivist culture of the Bangladeshi system of governance aggravates the problem. Although there are elections, the respective political parties serve their own electorates. There is no culture of negotiation and compromise; time and again it is "we" against "them". This is also manifest at the local level and between the different departments. The technology-minded BWDB does not consider uneducated farmers as negotiation partners, farmers have no confidence whatsoever in the officials. The different parties, therefore, remain at loggerheads.

In sum, there is a difficult shift going on between a technological regime of central control and purposeful action by the government supported by foreign agencies towards a regime in which networking and participatory development play vital parts. A change towards a culture of give and take between parties seems conditional. Images of friend and foe now dominate all actions and expressions. A process of meaningful dialogue, in which people can reach compromises, could redress this. Building trust between government and farmers is essential. The transition in Bangladesh from a central to a more de-central river development and management regime bears the character of an "emergent transformation". It could succeed if actors and resources from inside the regime can be mobilized, in which top-down coordination could be helpful. In order to become embedded in society at large, grassroots organizations should connect themselves to other groups, including the state, e.g. through networking.

\section{China: transitioning towards river basin management}

Managing water resources in river basins has been gradually accepted in China as an effective approach to alleviate the emerging water stress (see for this section: [40-44]). The 2002 amended Water Law has introduced a combined administrative and river basin water management approach in order to initiate water resources management at the river basin level. To the present day, however, Chinese water resources management remains challenged by its fragmented and inefficient water institutions, the emerging water crisis, the degraded aquatic and terrestrial ecosystems and the risks of many large-scale hydraulic constructions such as the dams along the Yangtze. Furthermore, China has several large rivers with highly complex and dynamic conditions, e.g. the Yellow River. Development and management of these rivers incorporates dilemmas regarding water allocation, water quality, floods and changing river 
courses, water infrastructure, hydropower production and ecological degradation as well as regarding the institutional framework.

The recently initiated transition towards river basin management is an example of a "purposive transition". What should happen here is that the government increasingly involves various lower level stakeholders. This is not easy, considering the characteristics of the Chinese socio-political system. Due to a long-term tradition of a highly centralised administration, it is very challenging for Chinese society to move towards public participation in the process of water infrastructure planning and management in the short term.

However, public environmental awareness in China has gradually increased since 1994 when the first environmental NGO - Friends of Nature - was founded in Beijing. Since 2000, opportunities for public participation have greatly increased. The 2002 Environmental Impact Assessment Law suggests several methods to facilitate this, e.g. canvassing people's opinion and consulting experts, holding symposia and presentation meetings and organising public hearings. Until now, however, people still have limited influence on a variety of environmental assessment and decision-making issues in China. Triple Helix could be a relevant policy instrument. In general, the Chinese case shows that high centralization has to make way for a new combination of central and decentral control. This requires new modes of cooperation between people, for which Chinese society and culture have ample resources.

\section{Discussion and conclusion}

Present-day water problems require a combination of socio-technical system innovations and technological regime shifts in river basins, in one word: transitions. These transitions can follow several and changing pathways. Different trajectories succeeded one another in The Netherlands, each resulting in important improvements in water control. The significance and power of this argument appears from actual developments and challenges. New shifts are taking place in The Netherlands now, towards a Room for the Water regime and European IRBM. Whether these transitions will be successful, depends on the kinds of next steps that will be taken. The same applies to the cases in Bangladesh and China, where water transitions are taking place as well. Different trajectory types require different intervention methods. These tools, which implicate specific forms and ways of stakeholder involvement, are based on modern information and communication techniques, but they are also recognizable in history, at least in the Dutch case.

Involving stakeholders is essential in the process of water resources development and management, but several factors determine the scale and scope of their influence. A first limiting condition is system dynamics. Water services are organized through water-related socio-technical systems, the development of which displays the operation of system mechanisms, like momentum and the focus on reverse salients. The socio-political situation also conditions stakeholder engagement and the form it takes or may take. 
The lesson to learn, however, is that stakeholder participation is not an absolute success factor, as is sometimes suggested. Transitions can succeed with limited stakeholder involvement, e.g. the transition to national water management in The Netherlands. Little stakeholder engagement, however, can also be impeding. In China, IRBM is increasingly adopted, but its further development depends on the room for public participation. Further, a transition initiated by stakeholders can be complicated. The Bangladesh case shows a complex multi-stakeholder (and multi-actor) situation, which could provide the basis for a new national water management system, if conflicts can be resolved.

In general, the optimum form of stakeholder participation seems to depend on the context of the transition and the operating space of the system. In each and every situation the right balance should be found between a number of apparent opposites. Hierarchical systems, e.g., should be responsive to influences from below. Similarly, participative processes should be combined with central control. Shapes and routes will vary, dependent on socio-technical system conditions and as well as contextual factors and developments. Ultimately, people construct their own futures, helping and conditioning one another.

\section{References}

[1] Ravesteijn, W., Hermans, L. \& Vleuten, E. van der, Water systems. Participation and globalisation in water system building. Special issue of Knowledge, Technology \& Policy,14(4), 2002.

[2] Mulder, K. (ed.), Sustainable development for engineers. A handbook and resource guide. Sheffield: Greenleaf Publishing, 2006.

[3] Bressers, H. \& Kuks, S. (eds.), Integrated Governance and Water Basin Management. Kluwer Academic Publishers: Dordrecht/Boston/London, 2004.

[4] Kissling-Näf, I \& Kuks, S. (eds.), The Evolution of National Water Regimes in Europe. Kluwer Academic Publishers: Dordrecht/Boston/London, 2004.

[5] Kaijser, A., System building from below: Institutional change in Dutch water control systems. Technology and Culture,43(3), pp. 521-548, 2002.

[6] Kates, R.W. \& Burton, I. (eds.), Geography, Resources and Environment. Vol. 2: Themes from the Work of Gilbert F. White. The University of Chicago Press: Chicago, 1986.

[7] Hoekstra, A.Y. \& Huynen, M., Balancing the world water demand and supply, in: P. Martens \& J. Rotmans (eds.), Transitions in a Globalising World. Swets \& Zeitlinger Publishers: Lisse, pp. 17-35, 2002.

[8] Hermans, L., Actor Analysis for Water Resources Management. Eburon Academic Publishers: Delft, 2005.

[9] Hughes T., Networks of power. Electrification in Western society 18801930. The Johns Hopkins University Press: Baltimore, 1983.

[10] Vleuten, E. van der, Infrastructures and societal change. A view from the Large Technical Systems field. Technology Analysis \& Strategic Management, 16(3), pp. 395-414, 2004. 
[11] Hughes, T.P. (1987). The evolution of large technological systems. In Bijker, W.E., Hughes, T.P. \& Pinch, T.J. (eds.), The social construction of technological systems. New directions in the sociology and history of technology. MIT Press: Cambridge, Mass. / London, England, pp. 51-82, 1987.

[12] Ravesteijn, W., Dutch engineering overseas: The creation of a modern irrigation system in colonial Java. Knowledge, Technology \& Policy, 14(4), pp. 126-144, 2002.

[13] Poel, I.R. van de \& Franssen, M.P.M., Understanding technical development: the concept of "Technological Regime". International Journal of Technology, Policy and Management, 2(4), pp. 355-360, 2002.

[14] Ravesteijn, W., Irrigation development in colonial Java: The history of the Solo Valley works from a regime perspective. International Journal of Technology, Policy and Management, 2(4), pp. 361-386, 2002.

[15] Disco, C. \& Vleuten, E. van der, The politics of wet system building: Balancing interests in Dutch water management from the middle ages to the present. Knowledge, Technology \& Policy, 14(4), pp. 21-40, 2002.

[16] Rotmans, J., Transitiemanagement: sleutel naar een duurzame samenleving. Assen: Van Gorcum Uitgeverij, 2003.

[17] Rotmans, J., Kemp, R. \& Asselt, M. van, More evolution than revolution: Transition management in public policy. Foresight, 3(1), pp. 15-31, 2001.

[18] Geels, F.W., Processes and patterns in transitions and system innovations: Refining the co-evolutionary multi-level perspective. Technological Forecasting \& Social Change, 72(6), pp. 681-696, 2005.

[19] Geels, F.W. \& Schot, J., Typology of sociotechnical transition pathways. Research Policy, 36(3), pp. 399-417, 2007.

[20] Rostow, W.W., The Stages of Economic Growth: A Non-Communist Manifesto. Cambridge University Press: Cambridge: 1960.

[21] Berkhout, F., Smith, A. \& Stirling, A., Socio-technical regimes and transition contexts. In: Elzen, B., Geels, F.W. and Green, K. (eds), System Innovation and the Transition to Sustainability. Edward Elgar Publishing: Cheltenham/Northampton, pp. 48-75, 2004.

[22] Smith, A., Stirling, A. \& Berkhout, F., The governance of sustainable socio-technical transitions. Research Policy, 34(10), pp. 1491-1510, 2005.

[23] Bruijn, J.A. de,Koppenjan, J.F.M. \& Kickert, W.J.M., Inleiding: Beleidsnetwerken en overheidssturing. In: Koppenjan, J.F.M., De Bruijn, J.A. \& Kickert, W.J.M. (eds.), Netwerkmanagement in het openbaar bestuur. Vuga: The Hague, pp. 11-30, 1993.

[24] Kemp, R., Schot, J. \& Hoogma, R., Regime shifts to sustainability through processes of niche formation: the approach of strategic niche management. Technology Analysis \& Strategic Management, 10(2), pp. 175-195, 1998.

[25] Quist, J., Backcasting for a sustainable future: The impact after 10 years. Eburon: Delft, PhD thesis, Delft University of Technology, 2007.

[26] Kamp, L.M., Learning in wind turbine development: A comparison between The Netherlands and Denmark. PhD thesis, Utrecht University, 2002. 
[27] Sassen, S., Territory, Authority, Rights - from Medieval to Global Assemblages. Princeton University Press: New Jersey, 2006.

[28] Jong, M. de, Lalenis, K. \& Mamadouh, V. (eds.), The Theory and Practice of Institutional Transplantation; Experiences with the Transfer of Policy Institutions. Kluwer Academic Publishers: Dordrecht, 2002.

[29] Jong, W.M. de, Waaub, J. P. \& Kroesen, O., Cross-national policy transfer to developing countries: Prologue. Knowledge, Technology \& Policy 19(4), pp. 3-8, 2007.

[30] Ravesteijn, W. \& Kroesen, O., Tensions in water management: Dutch tradition and European policy. Water Science \& Technology, 56(4), pp. 105-111, 2007.

[31] Ven, G.P. van de (ed.), Leefbaar laagland. Geschiedenis van de waterbeheersing en landaanwinning in Nederland. Matrijs: Utrecht, 1993.

[32] Dubbelman, H., Maatschappelijke gevolgen in de waterbouwkunde. Delft University Press: Delft, 1999.

[33] Bosch, A., Om de macht over het water. Europese Bibliotheek: Zaltbommel, 2000.

[34] Co-ordinating committee Rhine, No frontiers for the Rhine. Inventory 2004 in the Rhine river basin. International Commission for the Protection of the Rhine (ICPR), Co-ordinating committee Rhine, 2005.

[35] Kaijser, A., System Building from Below: Institutional Change in Dutch Water Control Systems. Technology and Culture, 43(3), pp. 521-548, 2002.

[36] Alam M.M. \& Hirsch, D., A negotiated approach in ensuring use of local knowledge and capacity for water resources management. In: Alaerts, G.J. \& Dickinson, N.L. (eds), Water for a Changing World: Developing Local Knowledge and Capacity. Taylor and Francis: London, pp. 259-268, 2009.

[37] Firoozyar, F., Managing water resources: An exploratory study of water practices in the Netherlands and Bangladesh. Master thesis, Delft University of Technology, 2010.

[38] Jong, W.M. de\& Kroesen, J.O., Understanding how to import good governance practices in Bangladeshi villages. Knowledge, Technology and Policy, 19(4), pp. 9-25, 2007.

[39] http://www.freenet.victoria.bc.ca/environment/CLIMATE/tiempo/8.apr/ban gladesh.html

[40] Wang, Y., Li, L., Wang, X., Yu, X. \& Wang, Y., Taking Stock of Integrated River Basin Management in China. Science Press: Beijing, 2007.

[41] Ravesteijn, W., Song, X. \& Wennersten, R., The 2000 EU water framework directive and Chinese water management: experiences and perspectives. WIT Transactions on Ecology and the Environment 124, pp. 37-46, 2009.

[42] Song, X., Ravesteijn, W., Frostell, B. \& Wennersten, R., Managing Water Resources for Sustainable Development: The Case of Integrated River Basin Management in China. Water Science \& Technology, 61(2), pp. 499506, 2010.

[43] Song, X., Mulder, K., Frostell, B., Ravesteijn, W. \& Wennersten, R., Public Participation in Chinese Water Management. Proceedings of the Institution of Civil Engineers, Engineering Sustainability, forthcoming. 
[44] Song, X. \& Ravesteijn, W., Dilemmas in Water Systems Development in China. In: Mulder, K., Balas, D.F. \& Lente, H. van (eds.), What is Sustainable Technology? Struggles and dilemmas regarding articulations of Sustainable Development. Greenleaf: Sheffield, forthcoming. 